\title{
Four chapters in the history of Australian cardiology
}

\author{
G. E. BAUER* \\ M.B., B.S., M.R.C.P., F.R.A.C.P. \\ Cardiovascular Clinic, Sydney Hospital
}

In an endeavour to present the outline of the development of cardiology in Australia as a continuing process, gradually gaining its own individual characteristics, attention was arrested by certain outstanding individuals and important milestones. Rather than attempt to cover the entire subject, an undertaking too ambitious for the present study, four chapters are offered to illustrate the progress of the speciality on this continent. If they serve to stimulate interest in Australian cardiology their purpose will have been fulfilled and the writer amply rewarded.

\section{An early comparative physiologist}

George Britton Halford (1824-1910) was one of the most gifted comparative physiologists and experimental cardiologists of the mid-nineteenth century. His association with Australia began in 1862 when he was appointed, on the recommendation of Professor (later Sir James) Paget of Saint Bartholomew's Hospital, London, to the foundation chair of Anatomy, Physiology and Pathology in the first medical school to be established in the Colony at the University of Melbourne. By that time he had already gained a reputation as a distinguished medical scientist. Whilst still a medical student he demonstrated that the first, as well as the second, heart sound could be abolished by preventing venous return to the heart and thus confirmed that both sounds were of predominantly valvular origin. These results were published in The Lancet in 1851 (Halford, 1851)-more than half a century later investigators of lesser calibre have been credited with the same observation. Halford was an ardent visitor to the Zoological Gardens of London where he examined the hearts of the ostrich, apteryx, eagle, python, elephant and antelope. At times he would stealthily approach the animal in the still of the night, accompanied only by the keeper, and listen with transfigured fervour to its heart beat. The results of his researches were published in two monographs

*G. E. Bauer, 185 Macquarie Street, Sydney, N.S.W. 2000.
'The Action and Sounds of the Heart-a Physiological Essay' (Halford, 1860) and 'On the Time and Manner of Closure of the Auriculo-Ventricular Valves' (Halford, 1861) both of which make interesting reading to this day:

'In prosecuting my own inquiries asses and dogs have been subjects of experiment and the following method has been adopted: Chloroform was first administered to produce insensibility, then the trachea divided and the nozzle of a bellows inserted into the lower position, and artificial respiration maintained, the anterior position of the thorax removed or turned upwards. In this process it is necessary, occasionally, to drop some chloroform into the valve of the bellows, otherwise the animal may become conscious and disturb the operations.' On his appointment Halford was described by Sir Redmond Barry, foundation chancellor of the University of Melbourne, as 'conscientious, earnest, efficient and industrious' though lacking in 'showy and shining' abilities (Osborne, 1929). According to his own testimony he was scornful of speculation and fancy-'scientific advancement must not be left in such hands, it must be brought back and tested, both theoretically and experimentally'.

In 1864 he delivered at the Melbourne University three 'Lectures on the Heart' which were reprinted in the Australian Medical Journal, Volume 9 in the August, September and October issues of the same year (Halford, 1864). They remain a model of clear exposition, simple humour and good literary style and represent the first major contributions to cardiology in Australia. Halford recorded observations on the function as well as the structure of the pericardium, studied the mode of production of the apex beat by thrusting long pins through the thoracic wall of dogs and beautifully described the motion of the heart valves in great detail and with astonishing accuracy.

Later Halford became the first dean of the Melbourne Faculty of Medicine and when he retired from university life in 1896 , he was very much the 'old professor', his blazoning discoveries all but 
forgotten by new generations of students and teachers.

\section{A wild colonial boy}

A more colourful and certainly more controversial figure was Welsh-born Charles Evans Reeves, B.A., M.D., who published a book Heart Diseases in Australia in 1873, based on a 'more or less careful examination of between five and six hundred cases of Disease of the Heart' (Reeves, 1873). The book includes chapters on 'Chorea of the Heart', 'Nervous Palpitations of the Heart', 'Inflammation of the Pericardium (Pericarditis)', 'Diseases of the Valves of the Heart (Endocarditis)', 'Diseases of the Right side of the Heart', 'Hypertrophy of the Heart', 'Fatty Disease of the Heart', 'Aneurism of the Thoracic Aorta' and one on miscellaneous topics including rupture of the heart, cancer, hydatid and angina pectoris. The text contains perceptive descriptions of patients with calcific aortic stenosis, mitral stenosis with cerebral embolism, pulmonary thrombo-embolic disease, bacterial endocarditis, paroxysmal tachycardia, hypertensive heart failure and ventricular rupture following myocardial infarction, without always appreciating present-day accepted aetiological relationships. One paragraph has a prophetic quality:

'Only three of the 310 patients which presented themselves at the institution were suffering from angina pectoris. In each of the cases there were indications of ossification of the aorta and of the smaller vessels of the heart and pericardium. The arcus senilis was strongly marked in each case. Age however accounted for this, one being 60, one 67 and the third 73 years of age. In each case the pain occurred on exertion, ceasing on resting for several minutes, sometimes returning, sometimes not, on again walking. One case died from rupture of the heart. It may be, I think, expected that this disease will become more common than it is at present.'

British reviewers dealt harshly with Reeves' book. The Medico-Chirurgical Review, April 1874, complains of 'many palpable mistakes in orthography and pathology' that the resulting information is of doubtful value. The Review suggested that Reeves would have done well to omit the disparaging remarks on the works of his Australian confreres in his introduction. The chapter on chorea of the heart, which the author stated was very common in Australia, was said to be so exceedingly difficult to understand that the reviewer confessed his inability to recognize an actual case from Reeves' description.

Charles Evans Reeves was a much more remarkable gentleman than was recognized by his critics. Modesty and humility were not amongst his most discernible characteristics. Seventeen years earlier he bestowed a gift upon mankind, a book on Diseases of the Stomach and Duodenum published in London in 1856, which carried the following introduction:

'My object in writing the following pages has been to present to the world a comprehensive work on Disease of the Stomach and Duodenum. In addition to my labours during several years-passed in French and English hospitals-in parochial, dispensary and private practice, collecting cases, I have carefully examined every attainable work likely to assist my efforts.'

Demonstrating his extraordinary versatility Reeves published several other books, including Diseases of the Spinal Cord and Membranes, Hydrocephalus, Consumption, Softening of the Stomach in Australia and On a Simple Method of Treating Strictures.

Presented with such diversity one could perhaps be forgiven for picturing Reeves as a very capable charlatan. Therefore it is not altogether astonishing to read in the Medical Times and Gazette of 1859 (a) an account of a most unusual occurrence under the heading, 'Prosecution for Conspiracy under the Medical Act'. The Gazette reported that a John Edward Protheroe and Charles Evans Reeves appeared before a magistrate and jury in Dublin on a charge of fraud. The circumstances were 'very peculiar and extraordinary indeed'. The Registrar of the King and Queen's College of Physicians declared that in March 1857 a person giving his name as John Edward Protheroe of Store Street, Bedford Square, London, applied to the College for permission to be examined for a licence to practise medicine. On 6 and 9 April the said John Edward Protheroe was interviewed by the censors of the College. The result of the examination was most satisfactory and he later received his diploma. Information subsequently received by the College, with great consternation, suggested that the person who appeared before the examiners and received his diploma was not, in fact and truth, John Edward Protheroe, but an entirely different person, by name Charles Evans Reeves. After hearing a good deal of evidence the Court adjourned, fixing bail for the two accused at $£ 1000$; however, as bail was not entered into, the parties were removed to custody. When the case was resumed, Baron Richards, for the presiding magistrate, addressed the city grand jury and described the case as being of a very grave and serious nature. The jury, after a lengthy retirement, announced that they found true bills against John Edward Protheroe and Dr Evans Reeves who stood charged with conspiracy to defraud the College of Physicians. The two prisoners, the Crown and College consenting, pleaded guilty, entering into their own recognizance of $£ 100$ each, to appear for judgment at 14 days' 
notice, if called upon (Medical Times and Gazette, $1859 b)$.

History does not relate the final sentence but, not unpredictably, the remarkable Dr Reeves soon thereafter appeared on the Australian scene where he did not seek atonement in obscurity for long. In May 1861, the first issue of The Medical Record of Australia appeared in Melbourne, modestly claiming to be 'A Journal of Australian, European, and American Medicine, Surgery, Midwifery, Physiology, Medical Jurisprudence, Chemistry, Materia Medica and Pharmacy'. It was published twice monthly, the annual subscription rate was $12 \mathrm{~s}$ or $13 \mathrm{~s}$ delivered. The editor and proprietor was none other than the ubiquitous C. E. Reeves. Apart from a series of original articles, case reports, medical news, vital statistics and tables showing the prevailing winds, height of the barometer, temperature, rainfall and amount of negative electricity and ozone, the journal contained an advertisement for the preparation of candidates for various medical examinations, conducted personally or by correspondence. The editor, with great grace, offered intending contributors, in his 'Notice to Correspondents' column, an outline of the correct method of reporting cases and recording autopsy findings. The editorial policy of The Medical Record of Australia was almost invariably opposed to that of the Medical Society of Victoria, the ancestor of the Australian Medical Association, Victorian Branch and, as such, part of the medical establishment. Reeves disapproved of the appointment of George Britton Halford to the chair of Anatomy, Physiology and Pathology, apparently regarding certain local medical men, including himself, better qualified for this position. In 1863, the year after Halford's arrival in Australia, Reeves announced in his journal the intention of giving a free course of lectures on materia medica and chemistry, to be followed by others on medicine, surgery, midwifery, anatomy and physiology, a direct challenge to the new medical school.

Reeves died of Bright's disease and anasarca in 1880 at the age of 52 years. Perhaps it is a symbol of conciliation that he is buried in a small cemetery less than a few minutes walk from the new Australian Medical Association building in Royal Parade, Melbourne.

\section{The dawn of clinical cardiology}

The dawn of scientific clinical cardiology coincided with the introduction of electrocardiography into Australia by Montefiore David Silberberg in 1912. The unpreparedness of local medical practice for such a major advance may be appreciated by reading the presidential address of $R$. R. Stawell to the British Medical Association, Victorian Branch, in the previous year, entitled 'A review of recent clinical methods in the investigation of cardiovascular disorders'. This paper was concerned with a rather basic description of cardiac physiology and discussed in detail pulse tracings in conditions of sinus arrhythmia, extra systole and continuous irregularity of the heart, the so-called nodal rhythm, obtained with the polygraph of James Mackenzie, for whom Stawell obviously had an idolizing admiration. This was still the age where the word of the master determined scientific truth in preference to the experiment. Stawell's presidential address concluded by reproducing three electro-cardiographic tracings published by Thomas Lewis, showing 'fibrillation' vibrations, and expressing the hope that during the coming year Professor Osborne, a Halford successor occupying the chair of Physiology, might obtain an Einthoven string galvanometer 'so that within the near future we may be able to show some original records'. In the meantime the audience was advised to 'appreciate the polygraph as one of the most valuable clinical instruments of precision that has ever been presented to the profession'.

M. D. Silberberg was born in 1882, in a small Victorian country town, entered Queen's College at Melbourne University in 1901, 5 years after the retirement of Professor Halford, and graduated M.B.B.S. with honours in 1906. After spending the next few years as resident medical officer and registrar at the Melbourne Hospital and Children's Hospital, Melbourne, he proceeded to London in 1910 , probably at his own expense, to undertake postgraduate work. He was fortunate in obtaining the position of Clinical Assistant at the Mount Vernon Hospital for Diseases of the Chest which gave him the opportunity for cardiac research in the Heart Wards under the guidance of Dr (later Sir James) Mackenzie. He was introduced to Professor A. R. Cushny of the Pharmacological Department of University College Hospital, London, and then became associated with Dr (later Sir Thomas) Lewis who had already gained world-wide fame with the book Mechanism of the Heart Beat (1911) and many other publications based upon his work with the Einthoven string galvanometer. Silberberg's first papers, dealing with the action of digitalis and demonstrating a direct cardiac as well as a vagal effect of the drug, were well planned and executed exercises in clinical research (Silberberg, 1911, 1912b; Cushny, Marris \& Silberberg, 1912). They make interesting reading allowing us to forget the fact that they were written 60 years ago.

'Bill' Silberberg returned to Melbourne in 1912 bringing with him the first imported electrocardiograph machine (Fig. 1), a colossal piece of apparatus occupying, for many years, a third of the space of his consulting room and absorbing many of his hours in dealing with its idiosyncrasies. In 1912 he 


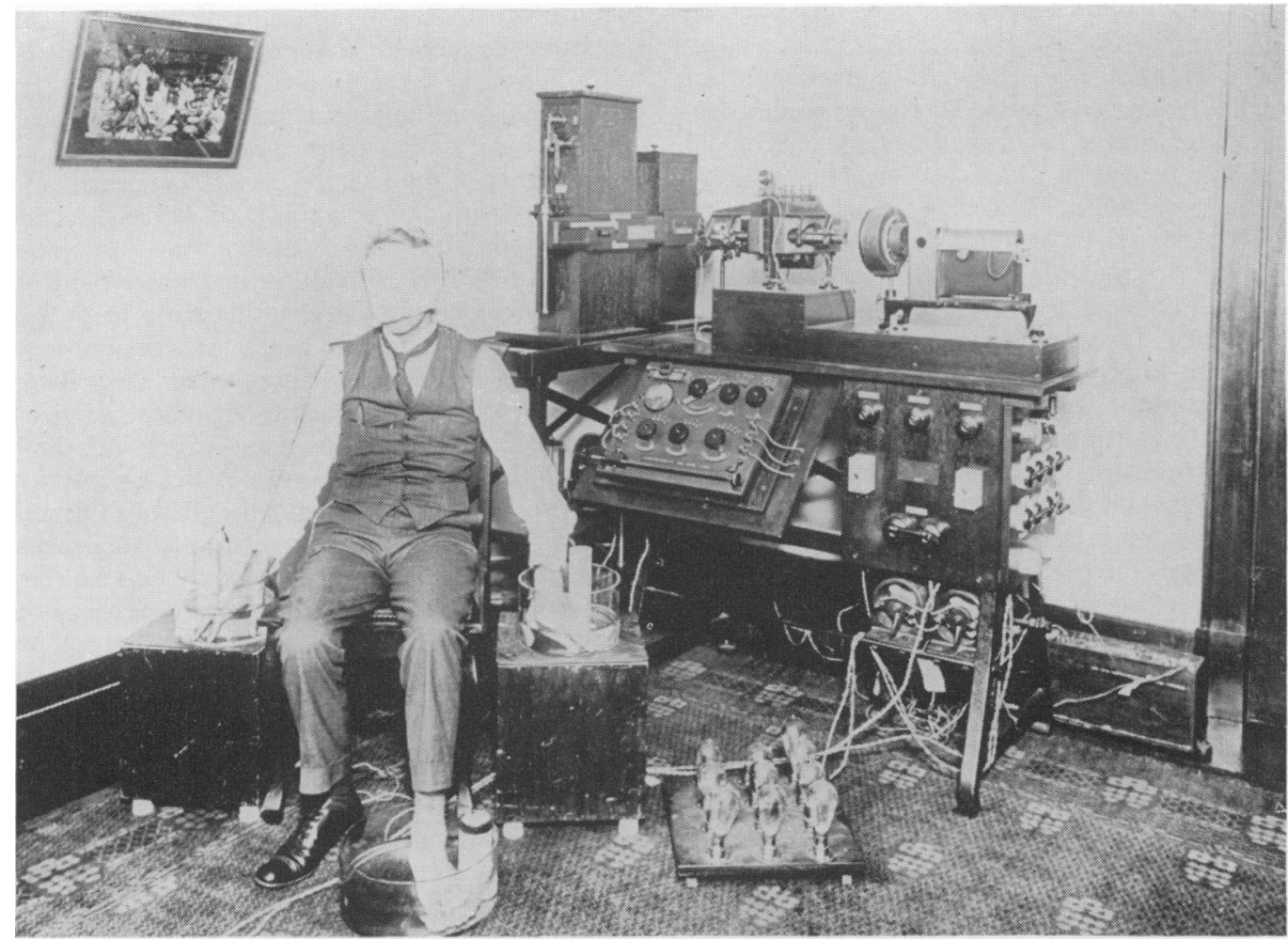

FIG. 1. Silberberg and his electrocardiograph (previously published in The Medical Journal of Australia, 1919, Vol. 1, p. 415).

read a paper before the Melbourne Branch of the British Medical Association entitled 'A Brief Account of the Electro-Cardiograph and its Clinical Application' (Silberberg, 1912a) in which were discussed the notched $P$ waves of left atrial hypertrophy, the precipitation of paroxysmal tachycardia by ectopic beats, the diagnostic importance of bundle branch block and the relation of ventricular fibrillation to cardiac arrest.

He might have felt a little isolated, far removed from the mainstream of cardiac research, but for the presence in Melbourne of his contemporary $H$. Hume Turnbull who had also spent some time in London working with James Mackenzie. Turnbull was obviously not only a good investigator who published important papers on paroxysmal tachycardia (1910), cardiac irregularities in childhood (1912) and the diagnosis, prognosis and treatment of cardiac disease (1914), but also a man with a critical and enquiring mind. On 1 May 1911 a Dr W. H. Summons read a paper on 'The Treatment of Cases of High Blood Pressure by means of Highfrequency Electric Currents' to the Victorian Branch of the British Medical Association, illustrated with pressure charts of six cases shown by lantern. With this method, known in France as D'Arsonvalisation, blood pressure could be lowered considerably more than by drugs, without any disagreeable result. The patient was placed within a large solenoid for varying periods of time, during treatment the patient felt a comfortable glow pervade the skin and this resulted in lowering of the blood pressure, according to Dr Summons, due to relaxation of arterial spasm. In the discussion $\mathbf{H}$. H. Turnbull expressed scepticism as to the value of the treatment and thought that in part, at least, the results might be due to suggestion. He mentioned that he knew of one case where the patient was put in the solenoid with excellent results but it was afterwards discovered that someone had forgotten to turn on the current.

In 1919 W. A. Osborne published 'An Electrocardiogram with some interesting features' in the Medical Journal of Australia. The tracing showed electrical alternation in a patient with ischaemic heart disease. An editorial comment in the same issue claimed that this was the first electrocardiogram to be reprinted in a medical journal in Australia and congratulated Professor Osborne on having started a new chapter of medical science in Australian medical literature. The editor had clearly overlooked 
the fact that Stawell and Silberberg had published tracings in the Australian Medical Journal, old and new series, as long ago as 1911 and 1912. It may be a point worthwhile recalling, and of not inconsiderable pride to present-day cardiologists, that the first paper published in the Medical Journal of Australia on 4 July 1914, Vol. 1 No. 1, p. 1, was by M. D. Silberberg, 'Notes on Cardiac Irregularities'.

Silberberg subsequently wrote important articles dealing with the use of quinidine in arrhythmias (1922), functional symptoms in heart disease (1928) and the prognosis of coronary artery disease (1938). In 1938 he became a foundation Fellow and Councillor of the Royal Australasian College of Physicians. He played an important role in the formation of the Australasian Cardiac Society, was elected its chairman in 1954 and became, subsequently, a Life Member. He was active in its affairs until shortly before his death in 1959 at the age of 76 years. His place in Australian cardiology is perhaps best summed up by his son, Frank, who wrote as follows: 'His published output was not large. I believe he was the first to use an Electro-cardiograph in Australia. For many years he and Hume Turnbull were the only recognised Cardiologists, at least in Melbourne. He is best remembered for his teaching, and his kindness and sagacity as a Physician. He always endeavoured to make known to the profession the latest advances in his subject, particularly the place of electrocardiography, the use of quinidine, the recognition of coronary occlusion and the importance of the psychosomatic aspects in cardiology'.

\section{The development of cardiac surgery and resuscitation}

The introduction of modern cardiac surgery in 1943 marked the beginning of a period of rapid development. Many years earlier, however, operations on the heart were carried out by Australian surgeons in Australian hospitals. At a meeting of the N.S.W. Branch of the British Medical Association held in Sydney on 30 September 1910, T. Fiaschi, discussing a paper by S. A. Smith on 'The Muscular Development of the Heart' and a demonstration by Dr Flynn of the conducting and contracting systems in cardiac muscle, described in some detail the operative procedure of repairing stab and gunshot wounds of the heart, making due reference to the original work of Rehn in Germany (Australasian Medical Gazette, 1910). Fiaschi, who was a very experienced surgeon with a dynamic personality, claimed that there was no instance in the whole field of operative surgery where the surgeon found himself at such close quarters with death as in this operation. He certainly gives the impression of having carried out the procedure on more than one occasion.

In March 1916 R. Scot Skirving, for over seven decades one of Sydney's most colourful medical personalities and, at that time contemporaneously, Honorary Consultant Physician to the Royal Prince Alfred Hospital, Sydney, and Honorary Surgeon to St Vincent's Hospital, Sydney, removed a missile from the pericardium of a soldier wounded in France (Scot Skirving, 1916). The surgeon reported that it was really quite thrilling to see the heart heaving and writhing before one's eyes like a squirming hairless reptile'. On the advice of Professor Starling, who was in the operating theatre, the heart was given frequent periods of rest from mechanical handling. Great care was taken to avoid opening the pleural cavities. The shrapnel was duly located in the posterior pericardium, between the pulmonary veins, and removed without complications. At the end of the report we are suddenly made aware of the half century that has passed since that operation when we read that the patient, after the operation, was kept in bed for $\mathbf{4 2}$ days and advised 'to wear some sort of breastplate of aluminium or felt to act as a shield to his weakened chest wall'.

Details of another early traumatic operation have been published by M. P. Susman (1963). An actress, aged 24 years, described as 'a comely creature and a character with an elegant dash of non-conformity and eccentricity', a member of the chorus 'second from the right, front row', shot herself in the epigastrium on 12 August 1919 in a solicitor's office during an argument about a love affair. She was taken to Sydney Hospital where H. Skipton Stacey repaired the wound but left the bullet embedded in the posterior wall of the pericardium. The patient continued to complain of pain and disability and insisted on the removal of the foreign body in spite of expert advice, from R. Scot Skirving among others, that it was best left alone. Mr Stacey relented and 4 months after the shooting accident re-operated in front of a large gallery, attracted, no doubt, by the glamour of the operation and patient, in an atmosphere described as dramatic and tense. Whilst the surgeon was groping for the bullet the heart stopped momentarily and the anaesthetist called out 'Hold hard, sir, I think you have done her in'. Fortunately the heart action quickly recovered and the foreign body was duly delivered and held high up in the air with a triumphant 'Gentlemen, the bullet' to a loud round of applause and bravos from the audience.

In 1932, 11 years before the beginning of planned cardiac surgery, W. J. Long, a country general practitioner in Bendigo, Victoria, successfully evacuated a cardiac hydatid cyst (Windsor, 1954). It is of interest that as long ago as 1884 John Davies Thomas, in his book Hydatid disease with special reference to its prevalence in Australia, collected thirty-five cases of heart hydatids from the literature, perhaps the largest series ever recorded. E. S. J 
King, later Professor of Pathology in Melbourne, created pericardial adhesions for the symptomatic relief of ischaemic heart disease. These experiences are incorporated in his book Surgery of the Heart, published in 1941 and based upon work for which he was awarded his third Jacksonian Prize by the Royal College of Surgeons.

Australian cardiac surgery, as we think of it today, was born on 15 July 1943, when, at the Royal North Shore Hospital, Sydney, B. T. (later Sir Benjamin) Edye successfully operated on a 6-yearold girl suffering from patent ductus arteriosus (Shallard, 1945; Edye, 1945). At that hospital Bruce Shallard had conducted, for a number of years, a clinic devoted to the study of congenital heart disease, probably the first dealing exclusively with a sub-branch of cardiology. These activities coincided with the discovery by Gregg (1941) and Swan et al. (1943) of the association of maternal rubella with congenital cardiac defects-the first convincing demonstration of the pathogenic effects of intrauterine viral infections. Ten of the first fourteen patients with patent ductus operated on by Edye and Susman made an excellent recovery, a very creditable result considering that the operations were carried out before the days of organized cardiac surgical teams, modern anaesthesia and effective antibiotics.

Almost simultaneously surgery of congenital heart disease began in Melbourne facilitated by war-time circumstances. P. W. Gebauer, a young thoracic surgeon from Cleveland, Ohio, towards the end of 1943, closed a patent ductus at the Royal Melbourne Hospital, assisted by C. J. (later Sir James) Officer Brown, who performed his first ductus operation at the Alfred Hospital, Melbourne, in March 1944. Officer Brown carried out a Blalock-Taussig shunt operation for the palliative relief of cyanotic congenital heart disease on 1 November 1947 and, less than a year later, on 19 October 1948, repaired a coarctation of the aorta, both 'firsts' in Australia. His work at the Alfred Hospital, Melbourne, is carried on by K. N. Morris, who in March 1957, assisted by G. Stirling, did the first Australian operations with total cardio-pulmonary by-pass.

Surgery for acquired valvular heart disease was introduced to Australia at Royal Prince Alfred Hospital, Sydney, when F. H. Mills performed the first mitral valvotomy in March 1951 (Mills et al., 1952). He had already performed operations for the relief of congenital defects with the backing of the diagnostic facilities provided by the Hallstrom Institute of Cardiology founded in 1949. The main credit for the establishment of this unit was due to J. K (later Sir Kempson) Maddox who had returned from the United States towards the end of 1946 with the first cardiac catheter seen in Australia. The research activities of the Institute are now directed by
P. Korner, who was appointed in 1968 to the first full-time chair of Cardiology in Australia.

An active surgical unit was established at $\mathrm{St}$ Vincent's Hospital, Sydney, by H. Windsor in 1951. Since March 1963 it has concentrated on prosthetic valve replacements and during the past 7 years has greatly added to an accurate appraisal of this type of cardiac surgery. Windsor and his colleagues were among the first to recognize the value of valve replacement in the treatment of antibiotic-resistant bacterial endocarditis (Windsor \& Shanahan, 1967). This team carried out the first heart transplant in Australia on 23 October 1968 (Gibson, Seldon \& Windsor, 1969).

H. D'Arcy Sutherland at the Royal Adelaide Hospital has had a large experience in closure of ventricular septal defects, an operation carried out in Adelaide with the amazingly low hospital mortality of $1.5 \%$. O'Brien and Clareborough of St Vincent's Hospital, Melbourne, introduced heterograft replacement of the aortic valve using pig and calf valves in February 1966, with excellent shortand long-term results. Cardiac surgical units are also functioning at Chermside Hospital, Brisbane; Prince Henry Hospital, Sydney; Royal Alexandra Hospital for Children, Sydney; Royal Melbourne Hospital, Royal Children's Hospital, Melbourne; Royal Perth Hospital and the Royal Hobart Hospital.

Mention should be made of the Australian contribution to our knowledge of cardiac resuscitation and coronary care units. In November 1962 D. G. Julian began routine monitoring of patients admitted to Sydney Hospital with acute myocardial infarction (Julian, Valentine \& Miller, 1964) and shortly thereafter G. Sloman introduced the technique at the Royal Melbourne Hospital (Robinson, Sloman \& McRae, 1964; Sloman, 1969). These two units were among the first in the world to put the concept of intensive coronary care into clinical practice and demonstrated reduction in mortality by the prevention and treatment of arrhythmic complications. It is not widely appreciated that reports of resuscitation of apparently dead patients have appeared in the Australian medical literature for over a century. In 1861 R. F. Hudson, of Ballarat, Victoria, reported the use of intermittent chest compression continued for several hours in a patient with cardiac arrest complicating aortic valve disease. In 1906 J. Ramsay of Launceston, Tasmania, successfully resuscitated a female who had collapsed under chloroform anaesthesia by artificial respiration, chest squeezing and internal cardiac massage. Pioneers are found in Australia also in the field of cardiology.

\section{Conclusion}

In presenting this selection of topics the omission 
of many important events and names in Australian Cardiology has been unavoidable. Many excellent accounts of cardiac pathology, aortic aneurysms and congenital malformations appeared in the medical literature of the last century. C. J. Martin, Professor of Physiology, University of Melbourne, described a sphygmomanometer in 1903, an adaptation of the Riva-Rocci apparatus which years later Sir James Mackenzie regarded as the best instrument of its kind available for clinical use. At the turn of the century J. Macdonald Gill, later Lecturer in Clinical Medicine, University of Sydney, Sydney Hospital Clinical School, published several polygraphic tracings including two from patients with heart block complicating acute rheumatism (Gill, 1909) and one from a patient with congenital heart block (Gill, 1911). Valuable papers on cardiac topics were published between the world wars by $\mathrm{H}$. Ritchie (1923), E. F. Gartrell (1927), J. C. Lidwill (1927), J. B. Cleland (1930), S. A. Smith (1931), A. J. Hood Stobo (1933), A. R. Southwood (1937), R. Whishaw (1937), A. W. Holmes à Court (1938) and many others.

A stimulus of great importance during the postwar period was the formation of the Australasian Cardiac Society in 1951, later renamed the Cardiac Society of Australia and New Zealand. Since its inception the society has grown by arranging regular scientific and clinical meetings and special conferences and by bringing to Australia, with the help of a magnificent gift from the R. T. Hall Trust and a grant from the National Heart Foundation, distinguished cardiac physicians and surgeons from other countries. The Cardiac Society of Australia and New Zealand played a significant role in the formation of the Asian-Pacific Society of Cardiology and now has the great honour of seeing one of its members, Sir Kempson Maddox, occupying the presidency of the world body, the International Society of Cardiology.

Since 1961 research, education and rehabilitation in the field of cardiology have been greatly assisted by the National Heart Foundation of Australia. The impact of the Foundation under the wise guidance of the National Board of Directors and the Medical Director, Dr R. Reader, has been felt in every cardiac department and unit throughout the Commonwealth. During the past 8 years some 330 Grants-inAid have been awarded to 120 different research groups in addition to many research, clinical and travelling fellowships. The Foundation has played a significant role in the establishment of rehabilitation units throughout the Commonwealth and pursues an active programme of professional and community education. The great strides during this decade are in no small measure due to the financial support provided by the Foundation.

\section{Acknowledgments}

My teachers, mentors and colleagues throughout Australia have been of invaluable assistance in collecting the historical facts presented. My special gratitude is due to Dr L. Bernstein, Sir James Officer Brown, Sir Clive Fitts, Associate Professor Bryan Gandevia, Dr J. Gardiner, Dr E. F. Gartrell, Dr T. E. Lowe, Sir Kempson Maddox, Mr F. H. Mills, Mr Ian Monk, Mr K. N. Morris, Sir Alexander Murphy, Dr D. O'Sullivan, Dr R. Reader, Dr F. Silberberg, Dr A. J. Hood Stobo, Mr H. D'Arcy Sutherland and Mr H. Windsor.

Mrs Alison Holster, librarian of the Royal Australasian College of Physicians, Miss Ann Tovell of the historical section of the Australian Medical Association (Victorian Branch) Library and Miss M. Rolleston, librarian, Australian Medical Association (N.S.W. Branch), have devoted much time and effort to this project. My secretary, Mrs Helene Dickson, has assisted with the preparation of the manuscript. Without the continuous encouragement of my wife this paper would have never been completed.

The sympathetic interest shown by all my friends convinces me that some day the complete history of cardiology in Australia should be recorded.

\section{References}

Cleland, J.B. (1930) Mortality from heart disease as revealed by post mortem statistics. Medical Journal of Australia, i, 579.

Cushny, A.R., Marris, H.F. \& Silberberg, M.D. (1912-13) The action of digitalis in therapeutics. Heart, 4, 33.

EDYE, B.T. (1945) Surgical treatment of patent ductus arteriosus. Medical Journal of Australia, ii, 362.

FiaschI, T. (1910) British Medical Association News; Proceedings of Australasian Branches, New South Wales. Australian Medical Gazette, 29, 553.

GarTRELL, E.F. (1927) The interpretation and clinical significance of certain electrocardiograms. Medical Journal of Australia, i, 528.

Gibson, H., Seldon, W.A. \& Windsor, H.M. (1969) A heart transplantation: 1. Clinical features. Medical Journal of Australia, i, 663.

Gill, J.M. (1909) Two cases of heart-block in acute rheumatism. Australian Medical Gazette, 28, 374.

GiLl, J.M. (1911) A case of congenital heart-block. Australian Medical Gazette, 30, 324.

GREGG, N.McA. (1941) Congenital cataract following German measles in the mother. Transactions of the Ophthalmological Society of Australia, 3, 35.

HALFORD, G.B. (1851) Original experiment on the sounds of the heart. Lancet, ii, 592.

HALFORD, G.B. (1860) The Action and Sounds of the Heart. John Churchill, London.

HALFORD, G.B. (1861) On the Time and Manner of Closure of the Auriculo-ventricular Valves. John Churchill, London.

HALford, G.B. (1864) Lectures on the heart. Australian Medical Journal, 9, 225; 9, 257; 9, 290.

Holmes À CourT, A.W. (1938) Factors in the prognosis of cardiac disease. Medical Journal of Australia, ii, 361 .

Hood Sтово, A.J. (1933) The clinical value of the electrocardiogram. Medical Journal of Australia, ii, 682.

Hudson, R.F. (1861) On aortic insufficiency, and on sudden death arising therefrom; with cases illustrative of the causes, pathology, and treatment of aortic diseases in general, as observed in Australia. Australian Medical Journal, 6, 235.

KING, E.S.J. (1941) Surgery of the Heart. Williams \& Wilkins, Baltimore.

Julian, D.G., Valentine, P.A. \& Miller, G.G. (1964) Routine electrocardiographic monitoring in acute myocardial infarction. Medical Journal of Australia, i, 433. 
Lidwill, M.C. (1927) Cardiac pain. Medical Journal of Australia, ii, 510.

MARTIN, C.J. (1903) The determination of the arterial blood-pressure in clinical practice. Inter-Collegiate Medical Journal of Australia, 8, 468.

Medical Journal of Australia, Editorial (1919) The study of heart disease. Medical Journal of Australia, i, 303.

Medical Times and Gazette (1859a) Prosecution for conspiracy under the Medical Act. College-Street PoliceOffice, Dublin. Medical Times and Gazette, 18, 89.

Medical Times and Gazette (1859b) Case of Messrs. Protheroe and Reeves. Medical Times and Gazette, 18, 176.

Medico-Chirurgical Review (1874) Heart diseases in Australia. Medico-chirurgical Review, 53, 448.

Mills, F.H., MaddoX, J.K., Blacket, R.B. \& Palmer, A.J. (1952) The surgical relief of mitral stenosis: a preliminary report. Medical Journal of Australia, i, 385.

O'Brien, M.F. \& Clareborough, J.K. (1966) Heterograft aortic valve transplantation for human valve disease. Medical Journal of Australia, ii, 228.

OSBORNE, W.A. (1919) An electrocardiogram with some interesting features. Medical Journal of Australia, i, 293.

OSBORNE, W.A. (1929) George Britton Halford: his life and work. Medical Journal of Australia, i, 64.

RAMSAY, J. (1906) Resuscitation of a patient apparently dead from primary heart failure. Inter-collegiate Medical Journal of Australia, 11, 496.

ReEves, C.E. (1856) Diseases of the Stomach and Duodenum. Simpkin, Marshall \& Co., London.

REEVES, C.E. (1873) Heart Diseases in Australia, with Observations on Aneurism of the Aorta. C. E. Reeves, Melbourne.

Ritchie, H. (1923) The use of digitalis in heart failure. Medical Journal of Australia, i, 119

Robinson, J.S., Sloman, G. \& MCRAE, C. (1964) Continuous electrocardiographic monitoring in the early stages after acute myocardial infarction. Medical Journal of Australia, $1,427$.

Scot Skirving, R. (1916) Shrapnel wound of the posterior wall of the pericardium: removal of the missile. British Journal of Surgery, 4, 96.

Shallard, B. (1945) Patent ductus arteriosus. Medical Journal of Australia, ii, 353.

SilberberG, M.D. (1911) The effect of atropine on the pulserate in cases under the influence of digitalis. Proceedings of the Royal Society of Medicine, 4, 192.

SilberberG, M.D. (1912a) A brief account of the electrocardiograph and its clinical application. Australian Medical Journal, 1 N.s., 488.
Silberberg, M.D. (1912b) Mode of action of digitalis in clinical work. Australian Medical Journal, 1 N.s., 745.

Silberberg, M.D. (1914) Notes on cardiac irregularities. Medical Journal of Australia, i, 1.

SilberberG, M.D. (1922) Quinidine sulphate in auricular fibrillation. Medical Journal of Australia, ii, 345.

Silberberg, M.D. (1928) Common cardiac problems: syncope, cardiac neurosis, praecordial pain. Medical Journal of Australia, i, 764.

Silberberg, M.D. (1938) Prognosis in coronary occlusion. Medical Journal of Australia, i, 298.

Sloman, G. (1969) Changing concepts in the care of patients with acute myocardial infarction. Medical Journal of Australia, i, 1157.

Sмiтн, S.A. (1931) Trauma and the heart. Medical Journal of Australia, ii, 575.

Southwood, A.R. (1937) Heart disease and national welfare. Proc. 23rd A.N.Z.A.S. Meeting, Auckland, p. 220. Government Printer, Wellington.

Stawell, R.R. (1911) A review of recent clinical methods in the investigation of cardio-vascular disorders. Australian Medical Journal, 16, 1.

Summons, W.H. (1911) The treatment of cases of high bloodpressure by means of high-frequency electric currents. Australian Medical Gazette, 30, 337.

Susman, M.P. (1963) An historical operation at Sydney hospital. Medical Journal of Australia, i, 288.

Swan, C., Tostevin, A.L., Moore, B., Mayo, H. \& Barham BLACK, G.H. (1943) Congenital defects in infants following infectious diseases during pregnancy. Medical Journal of Australia, ii, 201.

Tномаs, J.D. (1884) Hydatid disease with special reference to its prevalence in Australia. Government Printer, Adelaide.

Turnbull, H.H. (1910) Paroxysmal tachycardia accompanied by the ventricular form of venous pulse. Heart, 3, 89 .

Turnbull, H.H. (1912) Cardiac irregularities in childhood. Australian Medical Journal, 1 N.s., 444.

TuRnbull, H.H. (1914) Recent advances in the diagnosis, prognosis and treatment of cardiac disease. Australian Medical Journal, 3 N.s., 1517.

WINDSOR, H.M. (1954) Primary cardiac hydatid disease. British Journal of Surgery, 41, 541.

Windsor, H.M. \& Shanahan, M.X. (1967) Emergency valve replacement in bacterial endocarditis, Thorax, 22, 25.

Wishaw, R. (1937) Anxiety and the heart; with an analysis of cases. Medical Journal of Australia, i, 360. 